\title{
ПРИНЦИПЫ ВЗАИМОСВЯЗИ ИНСТИТУТОВ-КОРИДОРОВ Х-ЭКОНОМИКИ
}

\author{
В. Э. КСЕНЗОВА \\ кандидат экономических наук, доцент кафедры экономики и управления, \\ Белорусский государственный экономический университет, \\ С. В. КСЕНЗОВ \\ кандидат исторических наук, доцент кафедры международного бизнеса, \\ Белорусский государственный экономический университет,
}

\begin{abstract}
Аннотация
Предпринята попытка обосновать категории «духовный императив» (spiritual imperative), «институт-коридор» (channel institute), «институт-носитель информации» (data carrier institute). $B X$-экономике реализачия энергии в экономическое действие организуется через формирование собственности как института-коридора, задающего направление движения в соответствии с духовным императивом. Институты редистрибуции и координации адекватны институту собственности. При этом особое значение приобретает процесс делегирования прав распоряжения общественной собственностью отдельным людям или группам людей.

Ключевые слова: духовный императив, институт-коридор, институт-носитель информации, институциональная матрица, Х-экономика.
\end{abstract}

Abstract

The categories «spiritual imperative», «channel institute», «data carrier institute» are defined on our article. The implementation of energy in the economic action in X-economy is organized through the formation of the property of the channel institutes, in accordance with the spiritual imperative. Institutions of redistribution and coordination are adequate to the institution of ownership. The process of rights delegation for the disposition of the public property to individuals or its groups is particularly important.

Keywords: spiritual imperative, channel institute, data carrier institute, institutional matrix; Xeconomy.

\section{ВВЕДЕНИЕ}

Современное состояние любой экономики определяется эволюционными процессами в ее базисной институциональной матрице. Знание закономерностей данной эволюции позволит более четко идентифицировать тот этап, на котором экономика находится с точки зрения развития ее институциональной структуры. Мы предлагаем рассматривать механизм взаимодействия и взаимовлияния основных институтов X-экономики через призму совокупности основных принципов такой взаимосвязи. 
Фундаментом наших рассуждений являются идеи российских социологов Светланы Кирдиной и Ольги Бессоновой о наличии $\mathrm{X}$ - и $\mathrm{Y}$-экономик, о системе институтов раздаточной экономики. Их концепции восходят к мыслям о редистрибутивной экономике, высказанным Карлом Поланьи в середине XX века. Фундаментальная теория X-экономики нуждается в том, чтобы были разработаны принципы и механизмы ее прогностического применения. В ходе доработки данной теории нами были предложены новые категории «духовный императив», «институт-коридор», «институт-носитель информации».

Мы также опираемся на научные исследования, посвященные анализу специфики институционального устройства российского и белорусского обществ как обществ с X-матрицей. Вопросами специфики институциональной матрицы Беларуси занимаются такие ученые как С. Солодовников, П. Лемещенко, Е. Дорина. Российское общество с точки зрения институционального устройства изучают Р. Нуреев, В. Вольчик, Р. Капелюшников, Ю. Латов и др.

Без учета специфики институционального устройства как общества (этносоциума) в целом, так и его важнейших структурных составляющих, невозможно даже приблизительно прогнозировать реакцию социума на попытки фундаментальных трансформаций, в том числе и в сфере экономики. Поэтому фундаментальные исследования в области институциональной структуры национальной экономики являются не просто весьма актуальными. Без этих исследований нельзя адекватно определить вектор эволюции экономики как одной из составных частей в триаде базовой институциональной матрицы.

\section{РЕЗУЛЬТАТЫ И ИХ ОБСУЖДЕНИЕ}

В основе совокупности базисных принципов устройства институциональной матрицы конкретного этносоциума лежит духовно-идеологический императив, который можно понимать как объективно сформировавщийся "код» поведения членов этносоциума в исторический период становления последнего.

В основе этого «кода» лежит общность духовного восприятия мира и себя в этом мире в контексте принадлежности к определенному этносоциуму через устойчивую соподчиненность понятий «Я», «МЫ» и «ОНИ». Духовный императив реализуется в практической деятельности социума как духовно-идеологический императив и определяет формирование институтовкоридоров. Эти институты-коридоры призваны организовать в адекватном направлении движение энергии людей и их сообществ с целью самосохранения и развития данного этносоциума. Именно в рамках этносоциума с момента возникновения устойчивого взаимодействия между людьми формируется система «коридоров», по которым начинает передаваться, перемещаться энергия. Соответственно трем видам энергии формируются и три тесно взаимосвязанные системы «коридоров». Главная задача этой системы - обеспечить движение энергии в социуме, через которое достигаются, в конечном счете, цели существования и развития человека. Все институтыкоридоры в Х-экономике строятся на основе не только духовного императива, но и института 
собственности. Сюда относятся в первую очередь институты редистрибуции и координации экономической деятельности на основе централизованно принятых решений.

Постоянно эволюционирующий механизм взаимодействия базовых, а также базовых и комплементарных институтов приводится в движение «кодом» поведения, духовным императивом. Поэтому первым и важнейшим законом является принцип адекватности основных экономических институтов духовно-идеологическому императиву. В первую очередь это касается механизма взаимодействия институтов-коридоров. Их взаимодействие должно быть организовано таким образом, чтобы, в соответствии с заданным «кодом» поведения людей как элементов данного этносоциума, способствовать трансформации их внутренней энергии в действие в адекватном направлении с наименьшими трансакционными для социума издержками. Эта трансформация энергии в действие в заданном направлении позволяет достичь целей, обусловленных духовно-идеологическим императивом данного конкретного этносоциума.

Мы полагаем, что в сложной совокупности институтов, определяющих тип базисной институциональной матрицы, необходимо выделять институты-коридоры и институты-носители информации. Последние представлены нормами, правилами, обычаями, т.е. являются носителями закодированной информации. Однако они играют важную, но вспомогательную роль по отношению к институтам-коридорам. Последние можно представить как каналы движения в социуме духовной, социальной и психофизической энергии его членов (отдельных индивидов и их социальных групп различного уровня и масштаба) и трансформации этой энергии в конкретную деятельность с целью самосохранения и развития данного этносоциума. Энергия, трансформируясь из потенциального в актуальное состояние, не должна хаотично «распылиться» в окружающей среде. Объективно этносоциум выживет, если произойдет аккумуляция всех видов энергии (при их актуализации в действие) при четком направлении движения этой энергии. Институты-коридоры и призваны сыграть эту роль объективных каналов, по которым идет передача и трансформация энергии. Т. е институты-коридоры - это своеобразные ограничители, не дающие «распылиться» энергии отдельных субъектов. Возможность выжить у отдельного человека, не включаясь в эту систему институтов-коридоров, невелика.

Особая роль институтов-коридоров состоит в том, что они интегрируют передачу энергии (трансформацию в действие) в данном этносоциуме в однозначно определенном направлении. Это, во-первых, порождает эффект синергии, а во-вторых, обеспечивает устойчивость, повышает степень выживаемости этносоциума в конкурентной борьбе с другими этносоциумами («ОНИ») за ареал обитания и доступ к ограниченным ресурсам. Отдельный человек (член данного этносоциума) объективно «включается» в эту систему институтов-коридоров, получая адекватные информационные сигналы, ориентирующие его в выборе, направлении и скорости движения по этим коридорам. Данные сигналы мы и обозначили как институты-носители информации.

Исходя из существования двух типов базисных институциональных матриц - восточной (X) и западной $(\mathrm{Y})$ - можно говорить и о двух типах духовно-идеологического императива. Первый, характерный для Х-обществ, предполагает, что люди (члены конкретного этносоциума) 
подсознательно воспринимают сущность «МЫ» как более значимую, чем сущность «Я». Второй, отражающий специфику Y-обществ, предполагает обратную субординацию данных сущностей.

Экономика Республики Беларусь является достаточно типичной Х-экономикой. Поэтому можно утверждать, что механизм взаимодействия основных базисных институтов-коридоров определяется принципом адекватности духовно-идеологическому императиву, который предполагает движение и трансформацию энергии в направлении от сущности «Я»к сущности «МЫ». Этот «код» поведения в белорусском этносоциуме сформировался в период его становления - VIII-XII вв. Наши исследования по вопросам эволюции институциональной структуры белорусской экономики [1], [2], [3] показали, что, несмотря на трансформацию конкретных исторических форм базисных институтов и включение в базисную матрицу комплементарных институтов, данный код поведения в своей основе не изменился. И это надо учитывать, разрабатывая конкретные программы по преобразованию национальной экономики. Обозначим духовно-идеологический императив, характерный для обществ с институциональной Х-матрицей - X-императивом.

$\mathrm{X}$-императив определяет вектор движения и формы трансформации энергии в институтахкоридорах. Специфика данного направления заключается в том, что в социуме соблюдается четкая субординация интересов (в том числе и экономических). Интересы социума в целом воспринимаются подавляющим большинством членов данного социума как первичные по отношению к интересам отдельного человека (или хозяйствующего субъекта, если речь идет об экономике).

Рассмотрим более подробно базисные принципы взаимодействия в Х-экономике. В основе функционирования данной сферы лежит совокупность адекватных базисных институтовкоридоров - условно-верховная собственность, координация экономической деятельности на основе централизации, и редистрибуция. Эти три основных института-коридора формируют устойчивую совокупность взаимосвязанных и взаимозависимых каналов передачи энергии, вещества и информации с целью обеспечения жизнеспособности этносоциума. Они задают вектор данного движения, определяемый соответствующим «кодом» поведения - сущность «МЫ» подсознательно воспринимается как более важная, чем сущность «Я». В эту систему институтовкоридоров объективно включаются все хозяйствующие субъекты данного сообщества. Следовательно, они подчиняются духовно-идеологическому императиву в процессе своей экономической деятельности. В реальной действительности это проявляется следующим образом.

Проблема редкости благ и материальных ресурсов особую значимость в системе «коридоров» экономической сферы придает институту «собственности», т.е. совокупности ограничений в доступе к этим благам и ресурсам. Используя терминологию современной микроэкономики, можно говорить о формировании понятий «исключаемости» и «соревновательности» применительно к благам в их широком толковании.

Социальная энергия как энергия общности и взаимодействия индивидов актуализируется в противоречивом процессе выработки в рамках данного этносоциума адекватного института 
собственности. Коридор-ограничитель доступа к редким благам (включая ресурсы) создается посредством трансформации духовной и социальной энергии в действие. Примером действия института собственности в Х-экономиках является поместье. Поместьем в Московской Руси назывался участок государственной или церковной земли, данный царем или церковным учреждением в личное владение человеку при условии службы, т.е. как вознаграждение за службу и вместе с тем как средство для службы. Подобно самой службе, это владение было временным, но пожизненным.

Институт собственности изначально появляется как продукт реализации всех видов энергии - социальной, духовной и физиологической. В этом смысле понимание собственности только как экономической (и даже социально-экономической) категории не раскрывает ее глубинной природы. Такие категории морально-этического плана как «жадность», «скупость», «щедрость», «бескорыстие» и т.п. имеют самое непосредственное отношение к институту собственности. И именно духовно-идеологический императив определит всю совокупность этих оценочных (с точки зрения морали, принятой в этносоциуме) категорий. И в разных матрицах это будут разные совокупности.

В протестантской этике успешность в той или иной (любой полезной) деятельности мыслится как свидетельство богоизбранности, и под дарованной благодатью понимается в этом контексте призвание, трактуемое как призвание к конкретному виду деятельности и, в конечном счете, как профессия. Концепция призвания как богоугодности определяет отношение к собственности и прибыли - бережливость и приумножение капитала. Начиная от Лютера протестанты считают, что получить меньшую прибыль при возможности получить большую значит согрешить перед Богом. В православной этике все иначе. Православные мыслители С. Шарапов и М. Улыбышева пишут: «Дело в том, что спасение человека от богатства не зависит. Богатство, как и многое другое в нашей жизни, нейтрально по отношению к нашей участи в вечности... Можно обладать миллионами, но сердце иметь у Бога и спастись. Можно привязаться к деньгам и в бедности погибнуть» [4].

В X-обществе более масштабная социальная группировка априори признается социумом как более важная, чем меньшая по масштабу (и, как правило, включенная в большую). Соответственно, чем крупнее социальная группа, тем меньше у нее ограничений в правах на блага и ресурсы, находящиеся в зоне влияния данного этносоциума. Т.е. при движении от индивида к этносоциуму права собственности расширяются. Чем крупнее группировка, тем больше объектов собственности входит в зону ее прав. Соответственно, наибольший объем прав собственности (равно как и существенных объектов) имеет самая крупная социальная группировка - этносоциум в целом. Это логика собственности как института-коридора в X-матрице. Энергия индивидуального действия подчиняется объективно этой логике, когда преумножение собственности коллектива (расширение прав и уменьшение ограничений относительно использования благ для достижения целей существования и развития коллектива данного уровня) - более важная задача, чем преумножение собственности отдельного индивида. 
В концепции институциональных матриц С. Кирдиной данный институт обозначен как институт условной верховной собственности. Его характерные черты, отмеченные автором применительно к земельной собственности в России, адекватны господствующему в Х-обществе духовно-идеологическому императиву: «Во-первых, всегда существуют формальные и неформальные ограничения, в которых фиксируется право центральной власти в отношении земли, находящейся во владении и пользовании основных социальных субъектов. Во-вторых, верховная власть, являясь, по сути, собственником земли, определяет условия, выполнение которых обязательно для тех, кому эта земля передается во владение и пользование. Причем эта схема действует на всех уровнях иерархической властной вертикали - верхний уровень определяет условия для нижнего, в свою очередь, условия для него самого формируют стоящие выше звенья». [5]

Собственность как институт-коридор задает направление движения и реализации внутренней энергии в действие по доступу к редким благам и ресурсам и преобразованию ресурсов в блага. В этом действии объективно реализуются все виды потенциальной энергии человека в их совокупности. И при этом синергетический эффект усиливается при непротиворечивом сочетании этих видов энергии в процессе их реализации в конкретную деятельность человека. Поэтому важное значение приобретают институты-носители информации, которые дают человеку знание о том, куда ему направить энергию, как это лучше сделать, чтобы минимизировать трансакционные издержки действия. Это сродни дорожным знакам и правилам дорожного движения.

Все остальные институты-коридоры в экономической системе этносоциума строятся на основе не только духовного императива, но и института собственности. Они призваны организовать движение и реализацию энергии в заданном направлении с наименьшими трансакционными издержками. Сюда относятся в первую очередь институты редистрибуции и координации экономической деятельности на основе централизованно принятых решений. Эти институты всесторонне проанализированы в работах С. Кирдиной и О. Бессоновой.

Специфика сочетания индивидуальных, коллективных и общеэтносоциальных (общегосударственных в современной и более понятной терминологии) экономических интересов в Х-матрице порождает и специфическую роль отдельной личности в организации движения по такому институту-коридору как собственность. Расширение прав и уменьшение ограничений при движении от индивида к социальным группам само по себе может быть реализовано только через адекватную организацию коллективного действия.

Однако всякий раз принимать решение на «народном сходе» путем открытого обсуждения неэффективно с точки зрения трансакционных издержек. Поэтому объективно возникает необходимость делегирования права принятия решений относительно коллективных прав собственности отдельным индивидам (либо узким группам индивидов, в зависимости от масштаба и значимости коллектива и т.п.). Форм такого «делегирования» в Х-обществах неисчислимое 
множество, что определяется и этапом исторического развития, и уровнем развития технологий, и этногеографической спецификой и т.п.

Например, ссылаясь на опыт функционирования сельскохозяйственной общины после реформы 1861 года, С. Кирдина отмечает, во-первых, зависимость принятия решений относительно права пользования землей как объектом частной собственности на уровне отдельного двора от решений на уровне общины; во-вторых, четкую субординацию дворовой и общинной собственности на землю: «В условиях чересполосицы крестьяне продолжали быть связаны общими сроками сева и уборки урожая, которые определяла община. В общинном владении оставались угодья общего пользования (пастбища, выгоны, иногда леса). На общинном сходе решались дела о раскладке податей и т.д. Да и сама собственность крестьянского двора на землю могла быть реализована только внутри общины, смысл которой и состоял в совместном владении землей при индивидуальном ведении хозяйства каждым двором. Таким образом, действительно не представляется справедливым приравнять права крестьянина в составе подворной общины к правам реального частного собственника земли». [6]

Однако в любом случае «полномочный» представитель определенной группы в первую очередь берет на себя функцию распоряжения собственностью (в широком понимании последней) коллектива, сообщества. Его личная собственность не совпадает по объектам, правам и ограничениям с собственностью коллектива, интересы которого он представляет. Но полномочия его гораздо шире в вопросах распоряжения объектами, правами и ограничениями в отношении коллективной собственности, чем относительно его личной собственности. Он призван организовать движение своего коллектива по «коридору» института собственности в интересах этого коллектива как цельного субъекта хозяйствования. Эта организационная деятельность объективно в рамках X-матрицы формирует еще два института-коридора - институт координации через распоряжения сверху и институт редистрибуции (в примитивных обществах реципрокции).

В совокупности эти три института-коридора образуют объективную основу функционирования всей экономической системы Х-общества.

Таким образом, формируется специфическая роль субъекта, которому «делегируются» права распоряжения общей (коллективной) собственностью. Главное предназначение такого субъекта организация трудовой деятельности в рамках делегированных ему институциональных полномочий таким образом, чтобы обеспечить «вверенный» ему социум (в масштабах от «семьи» до «государства») необходимыми средствами существования и совершенствования. При этом предполагается, что личные экономические интересы данного субъекта однозначно подчиняются экономическим интересам социума, вторичны по отношению к последним. Противопоставление сущностей «Я» и «МЫ» актуализируется в данном случае как своеобразное «раздвоение» личности данного субъекта. С точки зрения общества он олицетворяет собой сущность «МЫ» и воспринимается не как отдельная личность в ряду других таких ж⿻е личностей, а как некая квинтэссенция совокупности всех представителей данного социума и их совместных интересов. 
Возникает специфическая иерархия интересов. Субъект-полномочный представитель призван выражать совокупный обобщенный интерес социума как единого начала «МЫ». Институт-коридор «условно-верховная собственность» определяет границы влияния субъектапредставителя в вопросах распоряжения объектами собственности социума в интересах этого социума, а также четко задает направление такого влияния. Т.е. объекты собственности социума должны быть включены в процесс трудовой деятельности его членов таким образом, чтобы в первую очередь удовлетворялись обобщенные экономические интересы социума как единого целого («МЫ»), даже если это не способствует (либо даже препятствует) достижению экономических интересов отдельных людей («Я»). В принципе предполагается, что объективная вторичность «Я» не должна в большинстве случаев провоцировать коллизий типа «А почему я должен страдать в угоду коллективу?» Ибо духовный императив, «код» поведения изначально ставит на первое место интересы социума (от «семьи» до «государства»). Вся система институтовносителей информации (обычаи, традиции, писаные и неписаные нормы и правила поведения, законы, приказы и т.п.), призвана направить реализацию энергии отдельной личности в действие от интересов «Я» к интересам «МЫ». В данном случае не ставится вопрос о правомерности и т.п. такого направления деятельности в свете глобальных проблем развития гуманизма и человеколюбия. Мы просто констатируем факт, имеющий в истории различных стран и народов с Х-матрицей многочисленные подтверждения (иногда чудовищные по своей жестокости!). Строительство Великой китайской стены, Беломорско-Балтийского канала и города Норильска, это только наиболее масштабные проекты в Х-экономиках с многочисленными жертвами, принесенными в угоду общественным интересам.

Субъект-представитель получает от социума «карт-бланш» на распоряжение объектами собственности. И вот здесь необходимо учесть, что личная (либо частная) собственность субъектапредставителя (как правило) не совпадает с общественной собственностью. Но при этом он фактически единолично получает возможность распоряжаться последней. Соответственно, объективно возникает противоречие интересов «внутри» самого субъекта-представителя, вызванное описанным выше своеобразным «раздвоением» личности. Как «Я» он желает максимизировать выгоду от личной собственности для себя, а как «МЫ» он обязан максимизировать совокупную выгоду социума от общественной собственности. И в данном случае, не смотря на внешнее сходство, это внутреннее противоречие субъектов-представителей в разных матрицах будет существенно отличаться по своему внутреннему содержанию и механизму реализации.

Принципиальное различие в данном случае обусловлено разной соподчиненностью «Я» и «МЫ» в восточной и западной матрицах. В Х-матрице субъект-представитель не просто олицетворяет собой коллективный интерес и в целом сущность «МЫ». Эта сущность и этот интерес первичны. . Поэтому решения, которые данный субъект принимает относительно

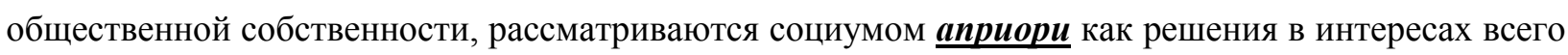
социума. И личные интересы не просто не должны идти в разрез с этими решениями, а должны 
подчиняться им. Если возникает противоречие личных интересов и принятых субъектомпредставителем решений, то первые должны быть принесены в жертву. Это, конечно, не исключает оппортунизма «внизу». Наличие и интенсивность такого оппортунистического поведения зависит от двух причин: 1) величина трансакционных издержек такого поведения для отдельного хозяйствующего субъекта; 2) степень адекватности решений, которые принимает субъект-представитель, действительным экономическим интересам данного социума. В данном случае на первое место выходит серьезная проблема оппортунистического поведения субъектапредставителя. Оппортунизм - это субъективное вмешательство в механизм взаимодействия институтов с целью использования последних в корыстных интересах.

Необходимо остановиться на характеристике принципов такого механизма взаимодействия применительно к базисным институтам-коридорам Х-экономики. Ведущее место в триаде «условно-верховная собственность - централизованная координация экономической деятельности - редистрибуция» принадлежит первому институту.

Задача-минимум X-экономики (как впрочем и Y-экономики) - обеспечить жизнеспособность этносоциума в степени, достаточной для гарантии его сосуществования с другими этносоциумами. Задача-максимум - обеспечить расширение ареала существования, в том числе и за счет других этносоциумов.

В совокупности принципы Х-экономики призваны трансформировать энергию в действие в заданном направлении. Условно-верховная собственность путем выше описанного делегирования полномочий отдельным представителям позволяет адекватно структурировать социум. Формируется специфическая иерархия субъектов, где отдельные субъекты - полномочные представители оказываются в центре, объединяя вокруг себя остальных членов социума и представляя собой выразителей совокупного экономического интереса. Когда первичный процесс построения такой системы завершен, начинается собственно процесс реализации базисной институциональной технологии: принятие решений относительно распоряжения общественной собственностью объективно предполагает координацию трудовой деятельности (в рамках «вверенного» коллектива) по использованию прав и объектов собственности и дальнейшее распоряжение процессами распределения и перераспределения результатов и условий этой деятельности среди членов социума. Причем этот процесс непрерывен. К тому же формы трансформации энергии в действие должны быть адекватны «коду» этносоциального поведения. Задача субъекта-представителя - обеспечить эту адекватность. Поэтому главной формой реализации трудовой деятельности является служебный труд. Категория эта введена в научный оборот О.Бессоновой.

Специфика движения энергии хозяйствующих субъектов в Х-экономиках заключается в обусловленной институтом условно-верховной собственности необходимости концентрации энергии для осуществления трудовой деятельности. Последняя предполагает деятельность по преобразованию ресурсов, находящихся в общей собственности, в продукт, предназначенный для потребления в рамках данного социума с учетом возможности внешнего обмена. 
В данном случае предполагается реализация Принципа легитимности субъектапредставителя (Центра) в вопросах принятия решений об организации трудовой деятельности в рамках социума. Должен быть реализован также Принцип первичности решений Центра относительно использования объектов условно-верховной собственности. Принципы легитимности и первичности формируют такие институты-коридоры Х-экономики как координация трудовой деятельности и редистрибуция через потоки сдач-раздач.

С. Кирдина так характеризует институт редистрибуции в Х-экономиках: «Редистрибуция означает преимущественно вертикальное движение материальных ценностей и услуг (но главное соответствующих прав) в рамках единой собственности. Здесь объективно требуется согласование хозяйственных трансакций не только между двумя совершающими их субъектами, но и между другими участниками хозяйственной жизни, которых прямо или косвенно могут затронуть действия двух выше обозначенных субъектов. Закон экономии трансакционных издержек приводит к тому, что вся совокупность необходимых согласований сосредоточивается в одном органе, который начинает выполнять функции Центра. Другими словами, если в ходе определенной трансакции потенциально могут быть затронуты интересы (права, ресурсы, условия деятельности) других хозяйствующих субъектов, то вместо того, чтобы обходить всех для получения согласований, или согласия на проведение трансакции, участники экономики обращаются в вышестоящий Центр, где аккумулируется основная необходимая информация». [7]

Здесь сразу необходимо отметить, что еще одним Принципом X-экономик является обязательное предоставление экономической информации в Центр (субъектупредставителю) и ее аккумуляция в Центре. Этот принцип реализуется через адекватные институты-носители информации - отчеты, докладные и служебные записки и т.п. формального и неформального плана.

Принципы легитимности Центра, первичности его в принятии решений касательно условноверховной собственности, аккумуляции информации в Центре определяют механизм движения энергии, информации и вещества в социуме через редистрибуцию как институт-коридор Xэкономики. Вследствие чего можно выделить Принцип трансформации энергии в действие только через опосредование Центром.

Таким образом, в Х-экономике предполагается концентрация энергии и информации в Центре на основе принципов легитимности последнего и первичности в принятии решений относительно условно-верховной собственности. Легитимность и первичность обеспечиваются реализацией духовно-идеологического императива, задающего направление движения энергии от «Я»к «МЫ». Соответственно данная совокупность базисных принципов предполагает особую роль субъекта - легитимного представителя. Он призван координировать потоки энергии, информации и вещества в Х-экономиках в интересах всего социума. При этом экономические интересы социума априори являются первичными и более значимыми, чем экономические интересы отдельного хозяйствующего субъекта. Это объективно формирует основание для 
возникновения противоречия интересов. Однако в большинстве случаев движение энергии от «Я» к «МЫ» снимает, «гасит» это противоречие.

Если образно представить себе это движение как речной поток по руслу в заданном направлении, который (поток) формируется у истока из множества однонаправленных ручейков, то появление ручейка с противоположным направлением движения внесет некоторые незначительные «водовороты», но не изменить движения потока в целом.

Задача Центра - регулировать это движение «потока» энергии в интересах всего социума через институты редистрибуции и координации. Схематично процесс влияния базисных принципов на механизм формирования и взаимодействия системы базисных институтовкоридоров в Х-экономике можно представить следующим образом:

I этап - Формирование X-императива, «кода» поведения:

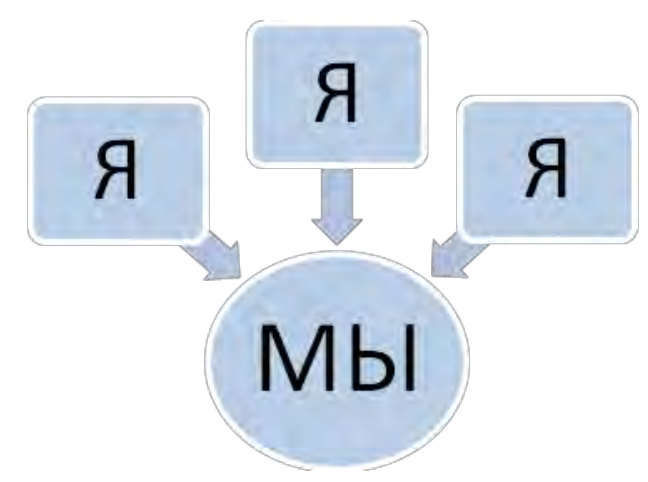

II этап - Формирование принципов X-экономики на основе «кода» поведения данного этносоциума:

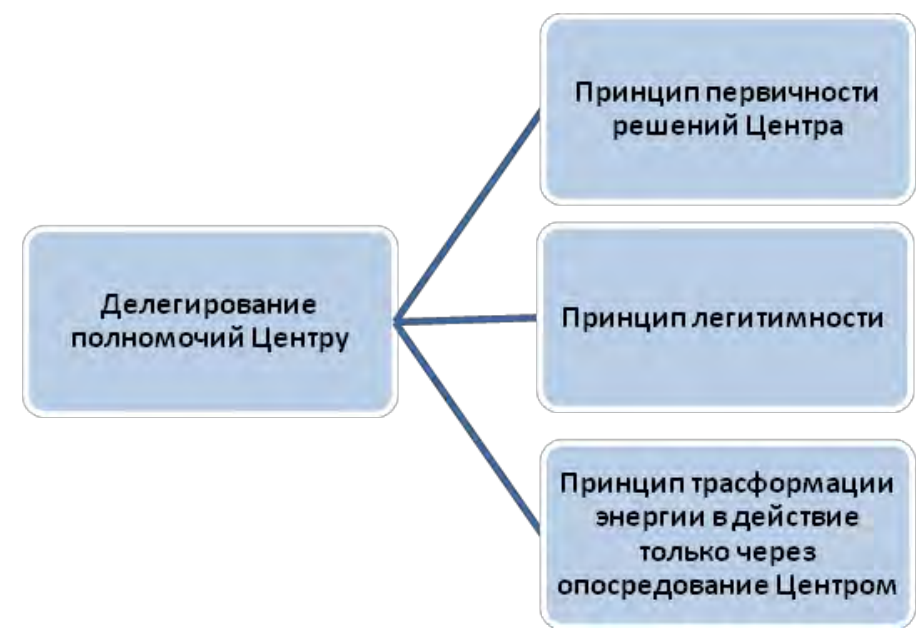


III этап - Формирование системы взаимосвязанных институтов-коридоров X-экономики:

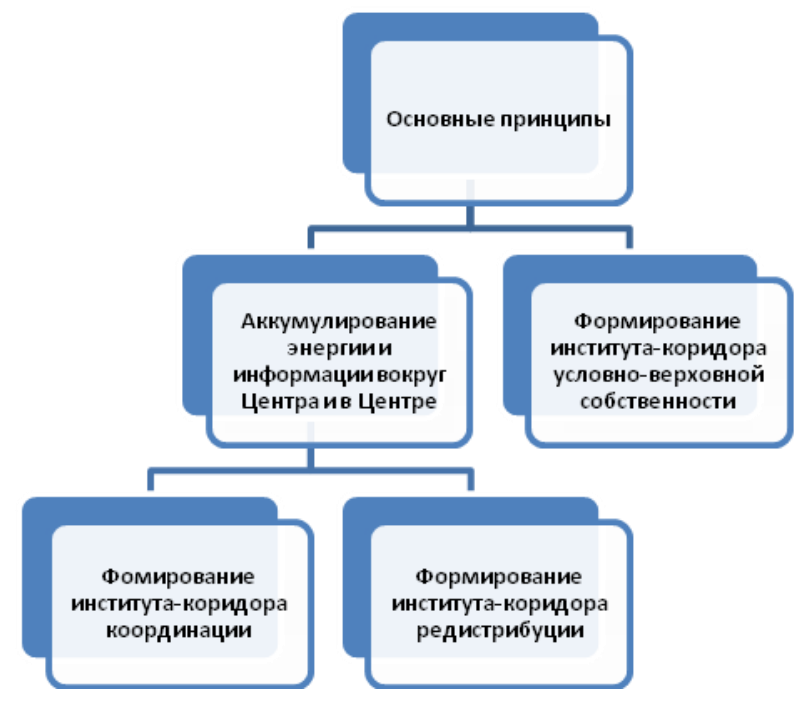

Рисунок 1 - Схема реализации основных принципов в Х-экономике

Поскольку все принципы реализуются одновременно, то поэтапность движения в схеме условна. Она необходима, чтобы показать объективность формирования механизма взаимодействия институтов-коридоров в Х-экономике и специфическую роль Центра (субъекта полномочного представителя) в этом механизме. Данная концепция объясняет, почему в Xэкономиках (да и в целом в этносоциуме с X-матрицей) субъект, олицетворяющий собой сущность «МЫ», получает столь значимые прерогативы в принятии решений о распоряжении условно-верховной собственностью и организации всей хозяйственной деятельности в социуме. Поэтому в Х-экономиках столь неоднозначна роль личности в организации трудовой деятельности. Человек, не получивший полномочий от социума, играет в этой деятельности подчиненную роль, так как формы и направления реализации его потенциальной энергии в действие определяет не он, а Центр. Человек, олицетворяющий начало «МЫ» и получивший такие полномочия, фактически единолично определяет формы и направления трансформации энергии в действие других членов социума. Отсюда - объективная неравнозначность, неравноценность отдельных личностей в Х-экономике, признаваемая и одобряемая социумом. Эта неравноценность будет проявляться на всех уровнях социальной организации - от семьи до государства в целом.

В этой связи не перестают быть актуальными проблемы эффективности функционирования $\mathrm{X}$-экономики. С точки зрения институциональной концепции эффективность может быть оценена через динамику и размеры социальных трансакционных издержек. То есть издержек функционирования всего механизма взаимодействия базисных институтов-коридоров. Эти издержки представлены как расходами Центра (государства) на организацию функционирования всей экономической системы, так и потерями, связанными с оппортунистическим поведением как Центра (субъектов - полномочных представителей), так и остальных участников хозяйственных процессов. Часть этих издержек (расходы государства) может быть определена достаточно точно, 
a часть (издержки оппортунистического поведения) - весьма приблизительно в связи с отсутствием достоверных данных.

Кроме того, эффективность Х-экономики зависит, во-первых, от адекватности исторических форм базисных институтов-коридоров и форм организации служебного труда, во-вторых, от адекватности комплементарных институтов, призванных играть балансирующую роль в механизме взаимодействия базисных институтов-коридоров и институтов-носителей информации. Поскольку Х-экономика в своем институциональном развитии проходит ряд институциональных циклов, то степень эффективности экономики во многом будет определяться фазой текущего цикла. В Х-экономиках на фазе перехода к следующему институциональному циклу (а Беларусь находится именно на этой фазе) важно интенсифицировать процесс имплантации в механизм взаимодействия институтов-коридоров комплементарных институтов. В первую очередь это относится к институтам частной собственности, рыночного обмена и конкуренции. На фазе спада институционального цикла трансакционные издержки нарастают ускоряющимися темпами в связи с неадекватностью форм базисных институтов. Поэтому общая эффективность Х-экономики объективно будет снижаться. Однако успешность перехода от фазы спада к фазе трансформации форм базисных институтов в Х-экономике в первую очередь зависит от решений именно Центра, о чем свидетельствует специфика механизма взаимодействия базисных институтов-коридоров Хэкономики. И именно Центр должен принять адекватные решения о внедрении комплементарных институтов. Если же он не справляется с данной задачей, то эти институты будут внедряться в стихийной (как правило нелегальной или полулегальной) форме, так как с точки зрения социума в целом они не получают соответствующей легитимности. В результате трансакционные издержки фактически не уменьшаются, а лишь трансформируются, меняют формы. А это может привести к резкому падению эффективности экономики в целом.

\section{ВЫВОДЫ}

Таким образом, мы пришли к выводу, что принципы взаимосвязи институтов-коридоров Хэкономики проявляются в следующем:

- адекватности основных экономических институтов духовно-идеологическому императиву;

- первичности решений Центра относительно использования объектов условно-верховной собственности;

- легитимности субъекта-представителя (Центра) в вопросах принятия решений об организации трудовой деятельности в рамках социума;

- трансформации энергии в действие только через опосредование Центром;

- обязательное предоставление экономической информации в Центр (субъектупредставителю) и ее аккумуляция в Центре. 
Учет данных принципов позволит более объективно прогнозировать различные варианты и сценарии эволюции национальной экономики. При этом необходимо учитывать также специфику исторического развития изучаемого этносоциума.

\section{ЛИТЕРАТУРА}

1. Ксензов, С.В. Особенности формирования базовых институтов малых наций (на примере Беларуси) / С.В. Ксензов, В.Э. Ксензова // Journal of Institutional Studies/ - 2010. - Том 2 №3. - С. 144-152.

2. Ксензов, С.В. Концептуальные подходы к сценариям изменений цивилизационных и малых базовых институциональных матриц / С.В. Ксензов, В.Э. Ксензова, К.К. Шебеко // Вестник Полоцкого государственного университета. Серия D. Экономические и юридические науки. - №10. - 2010.

3. Ksenzov, S. Basic and Complementary Institutes as the Factors of Economic Development in the Republic of Belarus / S. Ksenzov, V. Ksenzova, // Institution - State - Power. IX Annual Conference of the International Association for Institutional Studies. Knarkiv, Ukraine, October 12 -14, 2011/ Book of Abstracts. Knarkiv, 2011. - p. 40-41.

4. Шарапов, С. Бедность и богатство. Православная этика предпринимательства / С. Шарапов, М. Улыбышева. - Ковчег: 2013. - 320 с.

5. Кирдина, С.Г. "Х- и Ү-экономики: институциональный анализ / С.Г. Кирдина. [Электронный ресурс]. - http://kirdina.ru/book2/glava3.shtml - Дата доступа : 16.03.2009.

6. Кирдина, С.Г. "Х- и Ү-экономики: институциональный анализ / С.Г. Кирдина. [Электронный ресурс]. - http://kirdina.ru/book2/glava3.shtml - Дата доступа : 16.03.2009.

7. Кирдина, С.Г. "Х- и Ү-экономики: институциональный анализ / С.Г. Кирдина. [Электронный ресурс]. - http://kirdina.ru/book2/glava3.shtml - Дата доступа : 16.03.2009. 